\title{
Solución Sistémica a los Conflictos Nacionales
}

\section{Systemic Solution for National Conflicts}

Resumen - Se analiza cómo desarrollar una solución sistémica a los conflictos nacional articulando autodeterminación y solidaridad a través de un federalismo fractal.

\begin{abstract}
How to develop a systemic solution to national conflicts is analyzed by articulating selfdetermination and solidarity through a fractal federalism.
\end{abstract}

Palabras clave - autodeterminación, solidaridad.

Keywords - selfdetermination, solidarity

\section{Introducción}

Aplicando la metodología sistémica a los Sistemas Sociales destacan dos características:

1. Ni un Sistema Social ni sus subsistemas están aislados, sino interconectados con su entorno y entre sí.

2. Tanto los Sistemas Sociales como sus subsistemas son multiagentes, con múltiples centros de decisión.

Teniendo ello en cuenta, para aplicar dicha metodología a los conflictos en y entre Sistemas Sociales hay que estudiar la articulación de dos principios: autodeterminación y solidaridad.

\section{Autodeterminación}

A lo largo de la historia, la delimitación territorial entre Sistemas Sociales en forma de Estados ha ido cambiando. Pero durante siglos se regían por sistemas monárquicos en los que el monarca tomaba las decisiones asegurándose la sumisión de sus súbditos, y a través de un "juego de tronos" los cambios de fronteras, incluyend anexiones o secesiones, se resolvían a través de la guerra.

Pero desde finales del siglo XVIII, a raíz de la Revolución Francesa, los "súbditos" se van convirtiendo en "ciudadanos" con capacidad de decisión, y se desarrollan formas democráticas de gobierno.

En dicho marco, a finales del siglo XIX y principios del $\mathrm{XX}$ se va planteando que los conflictos "nacionales" sobre la delimitación territorial no se resuelvan mediante guerras sino a través de una "autodeterminación" en la que la ciudadanía de un territorio decida mayoritariamente sobre su adscripción a uno u otro Estado o su constitución como un Estado independiente.

La autodeterminación se plantea inicialmente en Europa, permitiendo la independencia de países como Polonia y Finlandia respecto de Rusia. Y no fue hasta el final de la Segunda Guerra Mundial cuando se estableció como una regla internacional para los procesos de descolonización.

No obstante, la aplicación del derecho de autodeterminación se realiza de forma desigual, en un mundo en el que persisten monarquías como residuos històricos, complementadas o no con formas democráticas.

Así, aunque tanto la Unión Soviética como Yugoslavia reconocían en sus Constituciones el derecho de autodeterminación, en el primer caso se ejercitó pacíficamente dando lugar a su separación en distintos 
Estados, mientras que en el segundo tuvieron lugar conflictos bélicos sobre la separación de sus componentes.

Y se han producido también comportamientos contradictorios. Así, Rusia rechazó la autodeterminación de Chechenia y posteriormente apoyó la de Crimea. Mientras que otros Estados europeos rechazaron la autodeterminación de Crimea tras haber apoyado la de Kosovo.

\section{Solidaridad}

Por otra parte, en la actualidad se hace patente la interdependencia en el conjunto del planeta, que hace inviable una independencia económica o ecológica más allá de la independencia política, de modo que las decisiones tomadas por un Estado afectan al resto.

En esta situación, por ejemplo, carece de legitimidad el abandono del acuerdo de París contra el cambio climático. Podría sugerirse irónicamente que en todo caso Estados Unidos debería erigir ya no un muro, sino una cúpula sobre su territorio para tragarse sus propios humos. Pero en tanto que ello resulte inviable, Estados Unidos no tiene derecho a contaminar al resto del planeta.

Igualmente, los incendios forestales no se detienen ante fronteras políticas, por lo que la lucha contra ellos debe gestionarse conjunta y solidariamente por encima de las fronteras.

Asimismo, cuando un río recorre distintos territorios (como es el caso del Ebro o del Segura), la gestión del mismo debe realizarse también conjuntamente. Y del mismo modo, en tanto que la lengua catalana es compartida por Cataluña, la Comunidad Valenciana y las Islas Baleares, debería gestionarse conjuntamente, igual que es razonable que en la Academia de la Lengua Española participen representantes de los distintos países en los que se habla.

Así, la autodeterminación sobre los límites territoriales no debería excluir la solidaridad entre los distintos países en un mundo interconectado.

Por otra parte, esa interconexión conlleva procesos de emigración entre distintos países. $\mathrm{Y}$ si la acogida de refugiados procedentes de conflictos bélicos ya está recogida en el derecho internacional, ello debería ampliarse a los refugiados procedentes de situaciones de miseria económica, frecuentemente generada por los mismos conflictos bélicos, o bien por la esquilmación de recursos naturales o los efectos del cambio climático.

Y la población inmigrante establecida de forma estable en un territorio debe tener reconocida en él sus derechos de ciudadanía, y no debería excluirse del eventual ejercicio del derecho de autodeterminación.

Naturalmente, serían rechazables tanto los procesos de sustitución de poblaciones como la limpieza étnica, que pervertirían dicho ejercicio. Pero la exclusión de la población inmigrante, y en algunos casos de la población nativa preexistente, es también una forma implícita de limpieza étnica, de la cual un caso palmario es el de los Rohingya en Myanmar, pero también el de la población palestina en el Estado de Israel.

Hay que tener en cuenta que el origen de conflictos y migraciones radica frecuentemente en la desigualdad entre distintos territorios. Por ello, su resolución requiere aplicar el principio de solidaridad haciendo efectivos derechos universales en todo el mundo, entre ellos el derecho a la sanidad y la educación.

Y dicha solidaridad requiere también la lucha contra los paraísos fiscales, estableciendo una homogeneidad fiscal de modo que todo el mundo aporte según su renta y reciba según sus necesidades, no como una forma de caridad sino de garantía de los derechos humanos, garantizando la posibilidad de trabajar ejercitando la educación recibida.

Y tanto la solidaridad como la autodeterminación deberían articularse sistémicamente a través de una federalidad fractal en los distintos niveles de la organización social, desde los actuales municipios, entidades infraestatales, los actuales Estados y las entidades supraestatales hasta abarcar al conjunto del planeta.

Naturalmente, la autodeterminación se aplicaría de forma distinta en los distintos ámbitos. Así, para los municipios limítrofes podría implicar su elección sobre la adscripción a distintas entidades infraestatales, igual que en un barrio podría atañer a la adcripción a distintos municipios o su constitución como un municipio autónomo.

Y por otra parte, si Europa estuviera organizada como una Federación (cosa que no ocurre con la actual Unión Europea), la autodeterminación de una parte de uno de sus Estados supondría simplemente cambiar la forma de adscripción en dicha Federación. 
Pero en la medida en que el principio de solidaridad esté establecido con carácter general, los cambios de adscripción tanto a nivel municipal como Estatal no podrían tener motivaciones egoístas para buscar ventajas comparativas, en un marco de homogeneidad fiscal y de garantía de los derechos humanos. Del mismo modo que el abandono de una determinada entidad o Sistema Social no podría suponer levantar fronteras contra el acogimiento de refugiados establecido también como una regla general.

Pues, a no ser que fuera viajando a Marte como propugna Elon Musk, nadie podría independizarse del planeta Tierra.

\section{Conclusiones}

La extensión de un federalismo fractal al conjunto del planeta Tierra es la vía sistémica para solucionar los conflictos nacionales articulando autodeterminación y solidaridad. 